\title{
El matrimonio como inversión. El caso de los Mendeville-Sánchez
}

\author{
Valentina Ayrolo \\ CONICET - Universidad Nacional \\ de Mar del Plata,* Argentina
}

Ubicándonos en la problemática de las relaciones personales, este trabajo tendrá como eje la observación del comportamiento social del matrimonio conformado por el primer cónsul de Francia en Buenos Aires, W. de Mendeville y la célebre criolla argentina Mariquita Sánchez, como recorte de la red total porteña de principios del siglo XIX. Nos centraremos en la discusión de las formas posibles de acceso, participación y usufructo del poder de un sector al que podríamos denominar "acomodado" y en la utilización que hacían de las redes de relaciones de su entorno. En el apartado $1 .^{\circ}$ presentaremos una breve descripción de la identidad de quienes durante 16 años formaron el matrimonio Mendeville-Sánchez. A continuación analizaremos el capital relacional de Mendeville y los beneficios que obtuvo de la inversión matrimonial. En el tercer apartado haremos lo mismo con María Sánchez. A modo de conclusión, analizaremos las particularidades de esta empresa matrimonial.

\begin{abstract}
El matrimonio lleva, en sí mismo, una doble contradicción: la disyunción sexual, que divide tanto como une. Esta mezcla de división y de unión se reproduce en el modo mediante el cual las redes ("agrupaciones") articulan la familia dentro de la sociedad global.
\end{abstract}

E. BotT

El tema de las relaciones personales y de las ventajas y posibilidades que ellas brindan ha sido tratado en numerosas oportunidades. Sin embargo, cada nuevo estudio reanuda la posibilidad de avanzar otro paso hacia la comprensión del fenómeno en lugares, tiempos y sociedades distintas.

La representación de la sociedad como una compleja suma de interrelaciones no es nueva. Empero la reflexión acerca de cuáles son los factores que producen, propugnan o desarticulan estas interrelaciones ha sido menos usual entre historiadores y sociólogos. No es nuestra pretensión despejar aquí todas las dudas relativas a la morfología y funcionamiento de la sociedad que nos ocupa, no obstante, procuraremos conocer aspectos que

* Quiero agradecer muy especialmente al dr. Eduardo Míguez por su tiempo y todas sus sugerencias y a Nicolás Quiroga por su invalorable ayuda.

1 Bott, Elisabeth: Familia y red social, Barcelona, 1971, pág. 289. 
sobre ella se desconocen. El estudio de estas "representaciones", ajustándolas a tiempos y lugares diferentes, es una forma válida para lograr un mayor conocimiento de aquellas sociedades tan lejanas a nosotros.

Sin abusar de las herramientas que proporciona al historiador la sociología se utilizan, para el trabajo que presentamos aquí, algunas de las nociones elaboradas en el marco de los estudios de network analysis por considerarlas apropiadas para abordar el tema, como así también usaremos parte de los conceptos que, a propósito de los sistemas de reproducción social, elaboró Pierre Bourdieu. Emplearemos aquí los referidos especialmente a las estrategias de reproducción entendidas como el ".. conjunto de prácticas, fenomenalmente muy diferentes, por medio de las cuales los individuos o las familias tienden, de manera consciente o inconsciente a conservar, a mantener o mejorar su posición en la estructura de las relaciones de clase". Estas estrategias estarían definidas en relación a la posición que se ocupa en el sistema de posiciones y de relaciones de posiciones sociales que Bourdieu define como campos. En una sociedad hay tantos campos como bienes preciados ésta tiene. El principio de diferenciación que cada uno de estos campos tiene es el del capital especifico, entendido como "conjunto de bienes acumulados que se producen, se distribuyen, se consumen, se invierten, se pierden...", 2 que está en juego. Bourdieu distingue principalmente tres variedades de capital además del económico: el social, el cultural y el simbólico. Citamos brevemente las definiciones de éstos últimos. El capital cultural es el ligado a los conocimientos, la ciencia, el arte. El social esta unido a lo que Bourdieu llama red durable de relaciones, a lo que podemos agregar que "el volumen de capital social que ha logrado un agente particular, no sólo depende de la extensión de la red de relaciones que él puede efectivamente movilizar en un momento determinado, sino también del volumen de capital económico, cultural o simbólico de cada uno de aquellos agentes a quienes está ligado por pertenencia a esa red". ${ }^{3}$ El capital simbólico por último es "el capital de cualquier especie, cuando es percibido por un agente dotado de categorías de percepción... cuando es conocido y reconocido como natural". ${ }^{4}$

Una vez ubicados en esta problemática, centraremos nuestro trabajo en el estudio de un caso concreto de matrimonio. El caso elegido permitirá

\footnotetext{
2 Gutierrez, Alicia: Pierre Bourdieu. Las prácticas sociales. Posadas, Argentina, 1995, pág. 34.

3 Ibídem, pág. 38.

4 Bourdieu, Pierre: "Espacio social y génesis de las clases", Espacios, n. . 2, Buenos Aires,
} 1985, pág. 28. 
avanzar en el conocimiento de parte de las interrelaciones que conformaban la sociedad porteña a través del matrimonio Mendeville-Sánchez, situado en Buenos Aires a principios del siglo diecinueve, cuando el país comenzaba, no sin serias dificultades, a organizarse interior y exteriormente. Valdría la pena entonces recordar aquí rápidamente el marco en el que vivió el matrimonio en cuestión.

Las repercusiones de la crisis monárquica desatada en España luego de la abdicación de Carlos IV y del posterior cautiverio de su sucesor Fernando VII se plasmaron, en el virreinato del Río de la Plata, en la revolución del 25 de mayo de 1810. Esta significó la toma del gobierno por parte del Cabildo de Buenos Aires, en nombre del rey cautivo. El intento de gobernar este extenso y joven virreinato estará signado por la guerra en las fronteras y al interior del mismo. El 9 de julio de 1816 un Congreso, reunido en la ciudad y provincia de Tucumán, declara la independencia de las Provincias Unidas de Sud América. Sin embargo la tarea de unificar ese espacio parecía muy difícil a pesar de la declaración de la independencia y de los esfuerzos que se realizaban para lograrlo. El año 1820 ilustra el quiebre de ese aparente orden. Luego de varios años de incesantes luchas entre caudillos provinciales, destinadas a definir la orientación de la organización nacional, las provincias asisten en esa fecha al desmembramiento del espacio construido desde 1810. A partir de allí, el nuevo "orden" político de las provincias estará regido por pactos interprovinciales y por esporádicos actos de unión. Las dos tendencias en esta lucha por el control del gobierno fueron federales y unitarios. De forma rápida y sucinta podemos decir que los primeros eran partidarios de una federación de estados y su representante máximo, en la provincia de Buenos Aires que es la que nos ocupa, fue Juan Manuel de Rosas, su gobernador durante dos períodos, 1829-1833 y 1835-1852, obteniendo en la última oportunidad poderes extraordinarios para el gobierno de la provincia y además el manejo de las relaciones exteriores de todas las Provincias, de lo que se conoce como la Confederación Rosista. ${ }^{5}$ Los unitarios propulsaban un gobierno centralizado, y soñaban con un estado liberal y moderno. Luego de la reunión de un congreso nacional en 1824, en el que se intenta legislar acerca de la unión de las provincias, en 1826 se elige como presidente a Bernardino Rivadavia, representante máximo en el poder de la facción unitaria, quien abandona el cargo tan sólo un año después. A partir del segundo gobierno

5 Para la reconstrucción histórica del período se recomienda ver Halperín Donghi, Tulio: De la revolución de independencia a la confederación rosista. Buenos Aires, 1987. 
de Rosas el panorama político parece aglutinado bajo la impronta federal rosista. En 1853, luego de su derrocamiento, se sanciona la Constitución Nacional que regirá sobre todo el territorio de la llamada entonces Confederación Argentina.

Este es el marco general de nuestro trabajo que tendrá como eje la observación del comportamiento social de un matrimonio como recorte de la red total porteña entendida esta como el conjunto general de individuos o enlaces ("tramas") posibles entre los individuos de una sociedad. ${ }^{6}$ Nos centraremos en la discusión de las formas posibles de acceso, participación y usufructo del poder de un sector al que podríamos denominar "acomodado" y en la utilización que para lograrlo hacían de las redes de relaciones de su entorno. En este trabajo tratamos de presentar, dentro de los límites que nos imponen las fuentes, la estructura interna de las redes personales de los Mendeville-Sánchez, así como el conjunto de vínculos que poseían, enmarcándolos siempre en la sociedad porteña de principios del diecinueve, cuya configuración ${ }^{8}$ permitió ejemplos como el que presentamos.

Las fuentes son principalmente las existentes en el Quai d'Orsay (Ministerio de Relaciones Exteriores de Francia, AMREF), donde consultamos correspondencia diplomática, memorias y documentos y papeles personales de los cónsules. Los informes que llegaban a París desde el Río de la Plata fueron, en un primer momento (1820-1827), los que viajeros, marinos o cónsules de otros territorios enviaban al gobierno contando el estado de cosas en la región.

Además, se consultaron fuentes del Archivo General de la Nación (AGN) de la Argentina, y la edición de la correspondencia de María Sánchez

6 Tomamos aquí la definición que cita Mitchell, Clyde: Redes sociales en situaciones urbanas., Manchester, 1969, como de J.A. Barnes. Este concepto es citado también por Moutoukias, Zacarías: "Narración y análisis en la observación de vínculos y dinámicas sociales: el concepto de red personal en la historia social y económica" pág. 231 en: Inmigración y redes sociales en la Argentina moderna. M. Berj - H. Otero (comps.), Tandil, 1995.

7 Aclaremos que la posición es acomodada fundamentalmente por su capital relacional y no tanto por el económico, como lo veremos en el ejemplo elegido.

8 Cuando hablamos de Configuración pensamos en la definición de Norbert Elias, quien la describe como la figura global siempre cambiante que forman los "jugadores" y que incluye no sólo su intelecto sino toda su persona. Elias, Norbert: Qu'est-ce que la sociologie? Paris, (1981) 1993, pág. 157. Pensando en la sociedad porteña como una configuración nos parece importante tener presente lo que Halperín denomina "la carrera de la revolución" que, aunque esta expresión define a las clases políticas, determina la suerte de sus familias también. Esta "carrera" estaría signada por "dos opuestas tentaciones: la de acercarse a esa fuente de tantos bienes y males [el nuevo estado] y tratar de emplearla en provecho propio, y la de mantenerse alejado de ese peligroso proveedor de esfímeros honores y riquezas" Halperín Donghi, T.: De la revolución de independencia... pág. 162. 
que realizó Clara Vilaseca en 1952. ${ }^{9}$ Existe también un archivo privado, perteneciente a la familia Lezica, que contiene papeles de los MendevilleThompson, con el que trabajó María Sáenz Quesada en su libro Mariquita Sánchez. Vida política y sentimental, editado en Buenos Aires en 1996.

\section{¿Quiénes eran los Mendeville?}

El matrimonio estaba conformado por Jean Baptiste Washington de Mendeville y María Josepha de todos los Santos Sánchez y Trillo, quien pasaría a la historia argentina como Mariquita Sánchez.

Mariquita había nacido en Buenos Aires el 1 de noviembre de 1786 en uno de los hogares más prestigiosos de aquel entonces. Era la única hija de don Cecilio Sánchez de Velazco y de doña Magdalena Trillo y Cárdenas, viuda en primeras nupcias de un riquísimo y poderoso comerciante de Buenos Aires llamado Manuel Del Arco. Cuando don Cecilio llegó al Río de la Plata en 1771 se encontraba sin dinero ${ }^{10}$ pero, gracias a su casamiento, logró una posición económica más que interesante, a la que acompañó con puestos políticos — alcalde de Barrio, alcalde de Primer Voto, regidor fiel ejecutor y defensor de Pobres a su Costa- que ayudarían a la consolidación de su posición y de su prestigio. ${ }^{11} \mathrm{El}$ abuelo de Mariquita, por el testamento de su primer yerno, ${ }^{12}$ estaba a cargo de la administración de la parte correspondiente a la herencia de su nieto, Fernando Joseph, único hijo vivo de la madre de Mariquita y de Manuel Del Arco. Sin embargo, Cecilio Sánchez iniciará con éxito acciones judiciales tendentes a obtener la administración de la fortuna de Del Arco. La temprana muerte de su medio hermano dejó definitivamente a Mariquita como única heredera del patrimonio de Del Arco. ${ }^{13}$

9 Vilaseca, Clara: Biografías de una época. Cartas de María Sánchez. Buenos Aires, 1952.

10 “... Sánchez de Velazco había sido hidalgo sin recursos cuando llegó a Buenos Aires en calidad de maestre de la fragata "La Sacra Familia" en 1771. Como no regresó, se le consideró desertor. Su negativa a regresar se explica porque el mismo año de su arribo había casado con Magdalena Trillo, viuda de Manuel Del Arco, poderoso comerciante de la plaza porteña. Aunque Cecilio careciera de bienes, su condición de español y su disposición al trabajo eran condiciones suficientes para aspirar a la mano de tan rica señora...”. Saénz Quesada, María: Mariquita Sánchez.Vida política y sentimental. Buenos Aires, 1996, pág. 21.

11 El dato aportado por Lidney para Guadalajara es para tener en cuenta en el caso que analizamos: "Dado que la función primordial del gobierno municipal en esta época era la regulación de la comercialización de productos agrícolas locales...las familias de élite se aseguraban el acceso a estos reguladores del mercado colocando a algunos de sus miembros al servicio del cabildo". Lidney, R.: Haciendas and economic development. Guadalajara, Mexico, at Independence. Austin, 1992, pág. 80.

12 AGN, Sucesiones, n. ${ }^{\circ}$ 3862, Manuel Del Arco, año 1768.

13 Ibídem, n. ${ }^{\circ}$ 3865, Manuel Del Arco, 1787. 
Vale la pena recordar algunos detalles significativos de la vida de esta mujer. En tiempos de la Independencia tuvo una actuación destacada al lado de su primer marido, Martín Thompson, apoyando a los independentistas que se reunían en su salón de tertulia. Conocido desde tiempos coloniales, había sido cerrado en 1804, al morir don Cecilio, y reabierto luego del primer casamiento de Mariquita en 1805. Este salón sería un lugar de encuentros privilegiado durante toda la primera mitad del siglo XIX, aunque intermitentemente, debido a algunas ausencias forzadas de su anfitriona. Cuenta la tradición que fue allí donde se escuchó por primera vez el Himno Nacional Argentino y que ella, junto con otras mujeres de patriotas, confeccionó las primeras escarapelas que se lucirían en la Semana de Mayo, comienzo oficial del movimiento que llevaría, en 1816, a la Declaración de la Independencia de las Provincias Unidas de Sud América, más adelante República Argentina.

A pesar de que estos hechos la convierten en una activa protagonista de los acontecimientos políticos de la época, son los entretelones de su primer matrimonio los que marcarían la excepcionalidad de su caso y, según se dice, inspirarían la obra El sí de las niñas de Fernández de Moratín, estrenada en un teatro porteño en 1805.

Su padre le negó el permiso para casarse con Martín Thompson y López Cárdenas, ${ }^{14}$ el novio "que ella había elegido". En 1804, apenas muerto su padre, Mariquita y su novio apelaron al virrey Rafael de Sobremonte ${ }^{15}$ para que éste la autorizara a contraer matrimonio, ya que su madre también se oponía a la boda. Los padres de Mariquita habían elegido como esposo de la niña a Diego Del Arco, sobrino de doña Magdalena pero, a pesar de los argumentos esgrimidos por su madre, ${ }^{16}$ el virrey falló a favor de la joven pareja.

14 Martín Thompson (1771-1819) perdió a su padre de muy niño; su madre, cumpliendo una promesa que le había hecho a su marido, ingresó en el convento de las Hermanas Carmelitas, dejando al niño a cargo de su padrino, el poderoso Martín de Altoaguirre.

15 Sobremonte fue virrey del Río de la Plata entre 1804-1807.

16 Dos eran las causas que esgrimía Magdalena Trillo para oponerse al matrimonio, según se observa en el juicio completo, desarrollado en Dellepiane, Antonio: Dos patricias ilustres. Buenos Aires, Coni, 1923 (25 ejemplares), págs. 147 a 173. Por un lado, la proximidad de lazos familiares de los dos jóvenes, que eran primos — primos segundos, según Zavalía Lagos, Jorge: Mariquita Sánchez y su tiempo. Buenos Aires, 1986, pág. 54- y por otro, la incapacidad de Martín Thompson para manejar su casa de comercio: "De la ineptitud de don Martín Thompson, joven por otra parte muy apropiado para la carrera que abraza [la de militar] pero inadecuado para correr con los negocios de la casa de la exponente..." (pág. 164, carta de Magdalena Trillo al virrey Sobremonte, sin fecha). Martín Thompson contesta: "Mi falta de instrucción e inteligencia para correr con los negocios de la casa es otro de los obstáculos que presenta para no convenir en nuestro enlace y aún propone como motivo de 
En 1816 Thompson fue enviado en misión a los Estados Unidos, para lograr, entre otras cosas, el reconocimiento de la independencia de las Provincias Unidas. Murió en altamar, en el viaje de regreso hacia Buenos Aires en 1819, dejando a Mariquita viuda con cinco hijos: Clementina, Juan, Magdalena, Florencia y Albina.

Jean Baptiste Washington de Mendeville había llegado desde Francia al Río de la Plata en 1818, condenado a tomar servicio en Buenos Aires como resultado de un "duelo desgraciado" ${ }^{17}$ Gracias a W. Parish Robertson sabemos que había sido "cumplido oficial de Bonaparte". ${ }^{18}$

Mariquita se casó en segundas nupcias con él en $1820^{19} \mathrm{y}$ tuvieron tres hijos: Julio, Carlos y Enrique, este último muerto a los 13 años. Lo poco que conocemos sobre las primeras actividades de Mendeville en Buenos Aires se lo debemos a la misma Mariquita, que cuenta que al llegar a la capital argentina, Mendeville daba clases de música, situación en la que lo conoció. ${ }^{20}$ Sabemos también, gracias a los papeles personales de los cónsu-

discordancia; pero cuando los negocios indicados, que de notoriedad se saben no ser otros que la material administración de unas fincas fructíferas...” (pág. 170). Pero ni siquiera Mariquita cedió a los ruegos de su madre que decía: "Si a la hija de una familia la llevara el aprovechamiento espiritual, si este fuere el deseo que la ocupara, si no atendiera tanto a otras cosas, como a la religión, entonces no se apartará del consejo de sus mayores, entonces no contrarrestará abiertamente a la voluntad de sus padres, porque la misma religión que afecta seguir se lo prohibe bajo culpa de pecado mortal..." (pág. 162); pero María Sánchez había escrito al virrey de forma terminante, mostrando determinación y diciendo que luego de agotar todos los medios de dulzura para con su madre, "[a]sí me es preciso defender mis derechos; o V.I., mándeme llamar a su presencia pero sin ser acompañada de la de mi madre para dar mi última resolución, o siendo esta la de casarme con mi primo, porque mi amor, mi salvación y mi reputación así lo desean y exigen...” (pág. 153).

17 Mendeville era originario del pequeño pueblo de Sos, en la Lot-et-Garonne. A pesar del pedido del acta de nacimiento que realizamos directamente al pueblo de Sos, no se pudo dar con el paradero de la misma. Los únicos datos de su filiación son los que nos proporciona el acta de matrimonio existente en el Archivo Privado de la familia Lezica [en adelante AL], en los que constan los nombres del padre, Santiago Mendeville, y de la madre, Julia Vinter (Sáenz Quesada, M: Mariquita Sánchez..., pág. 81). El motivo de su emigración ("duelo desgraciado") está en la compilación de cartas de Vilaseca, C.: Biografías..., pág. 11.

18 Robertson, J.P. y W. P: Cartas de Sud-América. III (1816-1820). Buenos Aires, 1950, Carta LII, pág. 64.

19 Con respecto a la fecha exacta de la boda existen varias opiniones. Clara Vilaseca y Jorge Zavalía Lagos fechan el matrimonio el 25 de febrero de 1819. María Sáenz Quesada, por el contrario, habla del 20 de abril de 1820 basándose en la fotocopia del acta de casamiento existente en el AL. Quesada dice: "No pudo haberse casado en esa fecha [por el 25 de febrero de 1819] porque todavía no había enviudado de Thompson [que se encontraba en misión en los Estados Unidos desde 1816 y cuya muerte es conocida en Buenos Aires, desde Montevideo, en diciembre de 1819]. Podía en cambio tenerlo de amante, como posiblemente ocurrió mientras no pudo legalizar la relación..." Cabe decir aquí que Thompson padeció de desórdenes mentales en los últimos dos años de su estadía en los Estados Unidos; un criado de la familia, que murió antes de embarcarse para el Río de la Plata, se encargaba de cuidarlo.

20 Vilaseca: Biografías..., pág. 308. 
les y a otros documentos, en los que consta sin precisar la fecha de inicio de esas actividades, que Mendeville tuvo una casa de comercio hasta que asumió su puesto de cónsul general en $1828 .{ }^{21}$ En realidad, más que una casa de comercio era una asociación comercial que compartía con el francés Edouard Loreilhe. La entidad, Mendeville, Loreilhe y Cía., estaba registrada bajo patente 28 en la calle Florida como "negociantes", dedicada a la importación de productos franceses. ${ }^{22}$

A partir de 1825 se abrirían para la familia Mendeville otros horizontes que, en parte, están relacionados con las características particulares de la pareja. Ese año, J.B. Washington de Mendeville fue nombrado inspector general de Comercio Francés y, a partir de 1827, abandonaría ese cargo para asumir el Consulado General de Francia en Buenos Aires. ${ }^{23}$ En este marco y a partir de ese momento comienza a dibujarse el tema que nos ocupa.

\section{La construcción de la red: el capital relacional de Mendeville y sus beneficios a través del matrimonio}

Recordemos que a través del caso Mendeville-Sánchez nos interesa ver si realmente podemos decir que el matrimonio es una inversión o puede funcionar como tal. Esta empresa matrimonial tiene como capital fundamental las relaciones que ambos cónyuges aportan y que en el caso que estudiamos tendrá algunas particularidades. Vale la pena aclarar antes de seguir adelante que este caso nos permite ver una de las formas de estructuración patrimonial posibles y válidas en el Río de la Plata del diecinueve. Así podríamos decir que veremos en nuestro ejemplo como es realizada la "segunda" estructuración familiar, la Mendeville-Sánchez, por la mujer de la pareja, quien parece apostar todas sus cartas al capital social.

Consideramos que el capital relacional de Mendeville es el conjunto de todas las relaciones que estableció en su carácter de cónsul francés, habitante de la ciudad de Buenos Aires durante 16 años y esposo de una porteña de familia tradicional. Si bien es cierto que Mendeville tuvo una

21 AMREF, Personnel Dossiers Première Serie, Mendeville, vol. 224 (pág. sin numerar).

22 Blondel, J.J.M.: Almanaque político y de comercio de la ciudad de Buenos Aires para el año 1826. Buenos Aires, 1825. El socio de Mendeville, originario de Burdeos, se casaría en 1826 con la hija mayor de Mariquita, Clementina Thompson.

23 Mendeville fue el primer cónsul general de Francia acreditado en Buenos Aires. Asumió sus funciones en 1828 al regresar de Francia, donde se encontraba por razones de trabajo. 
carrera destacada gracias en parte a Mariquita, los beneficios del enlace no fueron pocos para ambos. ${ }^{24}$

A juzgar por la lectura de los informes consulares, la intervención de Mendeville en la sociedad y en la política local parecería haberse dado en dos niveles. Por un lado, gracias a la efectiva mediación de su mujer, en un sector de la política local, y por otro, en sus propios negocios y amigos.

\section{La influencia de su mujer}

De acuerdo con las denuncias de sus contemporáneos, parece evidente que la influencia y/o la mediación de su mujer realmente existió. Un examen atento de la carrera de Mendeville permite observar que su evolución estuvo marcada por su matrimonio.

En primer lugar, ante la insistencia de varios enviados y viajeros galos sobre la importancia de que se designara un encargado de los asuntos comerciales franceses en Buenos Aires, el gobierno francés elegiría para el puesto a Mendeville. Como lo señalan el contraalmirante Rosamel y, más tarde, el barón de Damas:

"Si su majestad aprobara el proyecto que yo creo es mi deber presentarle de establecer un Inspector General de Comercio de Francia en Buenos Aires, yo le propondría se le confiera el título al sr. Mendeville, sujeto de V.M. establecido en el país desde hace varios años. El goza de una considerable fortuna y se encuentra en intimas relaciones con los personajes más influyentes". ${ }^{25}$

24 María Sánchez mantuvo una fluida correspondencia con la llamada Joven Generación del 37; entre esas cartas se destacan las que escribió a Juan María Gutiérrez y a Juan Bautista Alberdi, amigos de su hijo Juan. En una carta del 27 de mayo de 1863, Mariquita le decía a su amigo Alberdi: "Voy a hablar con usted como con nadie. He hecho acciones con mi marido más que heroicas. Dos veces ha estado su consulado por el suelo; yo lo he levantado. Mil veces, por sus locuras habríamos estado en el fango; mi prudencia y paciencia lo tapaba todo. No le he dado un disgusto: mi fortuna a manos llenas (...) yo no tenía más voluntad que sus caprichos. Fui muy infeliz...” Villaseca: Biografías..., pág. 307.

25 AMREF, Personnel Dossiers Première Serie, Mendeville, vol. 224. Con el mismo propósito que el barón de Damas, escriben el contraalmirante Rosamel y M. Angrand. Rosamel sugiere el nombramiento de Mendeville debido a su privilegiada posición en esos territorios en su "Note relative à Buenos Ayres et la Bande Orientale de la Plata" del 3 de julio de 1824 en: AMREF, Amérique du Sud "Memoires et Documents", 32 (1823-1836). M. Angrand, en "Note relative aux nouvelles Républiques de l'Amérique du Sud" (1823), pide un agente de comercio (AMREF, Amérique du Sud "Memoires et documents",31 (1810-1838) pág. 72). Los documentos transcriptos del AMREF, salvo advertencia, son originales en francés. En todos los casos la traducción es nuestra. [La cursiva es nuestra] 
Vemos así que, muy probablemente, su primer empleo al servicio de Francia tuvo relación con su considerable fortuna y sus conexiones en el país, ambas condiciones proporcionadas por su casamiento. Algunos años más tarde, en 1836, el cónsul interino Aimé Roger consideraba a Mariquita la artífice de la carrera de Mendeville. Opinaba que el señor Mendeville no sólo obtuvo la Agencia Comercial, gracias a su esposa, sino también el Consulado:

"Gracias al recibimiento lleno de cordialidad que hizo a los oficiales de la Marina Real, que fueron los primeros que visitaron el Río de la Plata, gracias al prestigio de su inmensa fortuna y también al estado precario de nuestras relaciones con los estados de América del Sud ella obtuvo para su marido el título de Agente General del Comercio de Francia y, más tarde, el de Cónsul General.”26

Finalmente, la ilustre señora, parecería ser la responsable de que el cónsul haya permanecido en su cargo durante un prolongado lapso una vez finalizada su designación. ${ }^{27}$

Sería ingenuo no ver que esta injerencia de Mariquita a favor de su marido, traducía la búsqueda indirecta de una porción de influencia y poder para ella misma en la sociedad porteña de la época. Sin embargo cabe señalar que este tipo de intervención sólo puede comprenderse como parte de la estructuración familiar a la que hicimos referencia en un principio. La injerencia de Mariquita puede leerse como una estrategia de reproducción familiar ${ }^{28}$ que visaba a la conservación del espacio social que le era propio desde su niñez y que había sido reforzada con su primer casamiento. Puede pensarse que ante la pérdida de cierto número de recursos económicos sólo le quedaba orientar su conducta hacia la maximización del resto de sus capitales, a saber el social, el cultural y el simbólico. La posibilidad de ser sede del Consulado de Francia, país por el que sentía gran admiración, le abría las puertas hacia el exterior desde la perspectiva del extranjero, posición nueva para ella que reforzaba su capital social y por supuesto simbólico.

26 AMREF, Argentine, Correspondance politique, Vol. 7 (1834-1836), "Direction politique" ínterin n. ${ }^{\circ}$ 3, Buenos Aires, 26 juin 1836, pág. 277 [el subrayado es nuestro].

27 Ibídem. Mendeville permaneció en Buenos Aires, a pesar de que estaba nombrado en Quito desde 1834, hasta la llegada del nuevo cónsul, Vins de Peysac, designado en 1835. Más detalles sobre el particular se encuentran en: Ayrolo, Valentina: Les problèmes et les acteurs de la vie politique au Río de la Plata, 1820-1836, vus par les diplomats français. Tesis de grado dirigida por el Dr. FrançoisXavier Guerra. Institut des Hautes Etudes de l'Amérique Latine, Universidad de París III SorbonneNouvelle, París, 1992, pág. 18 en adelante.

28 Bourdieu, Pierre: La distinción. Buenos Aires, 1988, pág. 122. 


\section{El nivel de las relaciones personales de Mendeville}

Respecto del segundo nivel del que hablamos, el de sus propios amigos, Mendeville aparece actuando con independencia del núcleo cercano a su esposa. Reformulando la idea de Bott que encabeza este artículo, diremos que el matrimonio divide y une, articulando la familia dentro de la sociedad en la que están inmersos. Así, la frecuentación de distintos medios por parte del marido y la mujer traía beneficios a la posición de la familia. ${ }^{29}$ Como es sabido, Mariquita se adhería al partido unitario y sus años más prósperos los pasó durante el gobierno de su amigo Rivadavia; sin embargo, los "amigos" del cónsul francés no parecían estar en el mismo bando. En realidad, su posición no deja de parecernos ambigua, ya que si bien es cierto que tuvo más problemas durante la gestión unitaria que durante la etapa federal, esto no indicaría de forma fehaciente su predilección por los últimos. ${ }^{30}$

Un hecho poco común, ocurrido en 1833, permitirá ver la relación del cónsul con el ámbito local. Contradiciendo por completo el principio de no intervención en asuntos internos del país en el que residían, principio que él mismo había esgrimido como argumento a la hora de forzar a los franceses a dejar las milicias locales, Mendeville comunicó a su gobierno que había colaborado con el gobierno federal para lograr un entendimiento entre partes. Aunque el informe más interesante es demasiado largo como para reproducirlo aquí completo, transcribimos algunos párrafos que fundamentan nuestro análisis. Mendeville había sido convocado como mediador para la confección de una lista única de candidatos del partido federal luego de la división que se había producido entre rosistas y lomos negros,

29 Familia que es imprescindible pensar como conformada de forma muy distinta a la familia actual de "invención reciente". Ver Bourdieu, Pierre: "El espíritu de familia". Razones Prácticas. Barcelona, 1997, pág. 127.

30 En un informe que envía al Quai d'Orsay en 1829 afirma haber tenido disidencias con el partido unitario. Suponemos que hace referencia a los conflictos acaecidos por el enrolamiento de soldados franceses en las milicias locales. El cónsul francés se opuso con vehemencia a ésto, llegando a amenazar a sus compatriotas con retirarles la ciudadanía si persistían en su actitud. Esta diferencia lo obligó a exiliarse con toda su familia en Montevideo hasta diciembre de 1829, cuando retornó a Buenos Aires con la promesa de Rosas de que no volvería a suscitarse un hecho parecido. Refiriéndose a la respuesta de Rosas a una carta que le había dirigido desde Montevideo, Mendeville dice en el post scriptum: “... s'il continue à suivre cette ligne de conduite, ce sera le héros et le bien faiteur de ces confrères, et le meilleur protecteur que puissent avoir les français parmi les hommes puissants du pays" (21 de mayo de 1829). Esto nos deja ver su preferencia, no por un color político, sino por aquellos que benefician su interés. AMREF, Argentine, Correspondance politique, Vol. 4 (maidécembre) 1829. 


\section{Apostólicos y Cismáticos ${ }^{31}$ según Mendeville. Los problemas entre estas dos facciones federales desembocarían en octubre en la revolución de los Restauradores, que preparó la vuelta de Rosas al poder. Al respecto Mendeville escribió el 16 de septiembre de 1833:}

“... los jefes del Estado [se trata de Juan Ramón Balcarce ${ }^{32}$ ] pusieron sus ojos en mí como si pudiera yo solo, en la situación actual, actuar como intermediario para una reconciliación. Habiendo respondido a las primeras propuestas que se me hicieron que podían contar conmigo para brindar todos los favores compatibles con mis deberes de agente de Francia, tuve inmediatamente conferencias particulares, no solamente con los ministros, sino con el Gobernador y su misma familia,...

Unos y otros pensaban que mi carácter de agente de una gran nación me situaba en una posición independiente (...) Por otro lado, la conducta que yo he tenido siempre, en mis funciones consulares me mantuvieron tan extranjero a los asuntos de los partidos, que conservé entre los hombres influyentes relaciones que ningún cambio político había alterado. Finalmente no sólo mi conocimiento de los acontecimientos sino también el carácter de todos los personajes influyentes debido a mi estadía de catorce años aquí completaba los medios de los que disponía para comenzar la negociación. (...)

El gobernador me respondió que yo conocía bien la situación del país y que él tenía demasiada confianza en mí como para no dejar a mi consideración el manejo de este tema."

\section{Luego de explicar cómo comenzó a negociar con Gregorio Tagle ${ }^{33}$} (lomo negro) y cómo planteó el acercamiento a Tomás Guido ${ }^{34}$ (rosista), explica:

"Ya he intervenido y he hecho intervenir a varios de mis amigos cercanos a algunos hombres influyentes del Partido Apostólico como lo son el sr. Maza y el

31 Ibídem, vol. 6 (1832-1833), n. 49

32 Balcarce, Juan Ramón (1773-1836): se opuso a los contrarrevolucionarios (1810) uniéndose al ejército liberador del norte al mando de Belgrano, en 1820 fue por corto tiempo gobernador interino de Buenos Aires, ministro de gobierno durante el primer gobierno de Rosas y electo gobernador de Buenos Aires en 1832, luego depuesto por los seguidores de Rosas. Wright, Ione S.; Nerhom, Lisa P.: Diccionario Histórico Argentino. Buenos Aires, 1990.

33 Tagle, Juan Gregorio (1772-1845): abogado, funcionario público, líder que encabezó sin éxito una serie de conspiraciones en contra de las reformas eclesiásticas de Rivadavia. Fue ministro de relaciones exteriores durante el directorio de Pueyrredón en 1817. En 1833 fue ministro de gobierno y ese mismo año era elegido para la Legislatura provincial, Rosas lo removió de su cargo en 1835 . Wright y Nerhom: Diccionario Histórico...

34 Guido, Tomás (1788-1866): general en la guerra de la independencia, funcionario gubernamental, diplomático. Guido fue activo miembro del gobierno de Rosas; prestó servicios como ministro (1829) e infructuosamente trató de impedir que éste renunciara en 1832. Luego del retorno de Rosas al poder, en 1835, Guido fue enviado como embajador a Brasil (1840-1852). Wright y Nerhom: Diccionario Histórico... 
sr. Anchorena, ex ministros, para hacerlos comprometer a que ellos mismos pidan en su partido lo que yo acordé con el señor Tagle: que se conforme una lista mixta de candidatos a la diputación.. ${ }^{35}$

Analicemos el trasfondo de estas declaraciones. Tenemos un negociador entre partes, elegido por su carácter neutral de agente extranjero, como argumenta en un momento de su informe, o por su conocimiento de los personajes implicados en el conflicto debido a su largo séjour en la ciudad, como señala después. Sea como fuera, fue a Mendeville a quien se le pidió la mediación y no a otro, según él mismo declara, por ser el único poseedor de la doble mirada local-extranjero sobre el asunto. Podemos decir entonces que esta situación lo convierte en actor indiscutido de la política del momento, aparentemente sin interferencia directa de su esposa.

Otro aspecto importante del informe nos permite ver cuáles son los procedimientos que utilizaba Mendeville para llegar a un acuerdo entre las partes. Por un lado, realizó entrevistas personales, incluso con las familias "atormentadas por la inquietud y las lágrimas ... por la amenaza que representan estos asuntos". ${ }^{36}$ Por otro, recurrió a sus amigos, ${ }^{37}$ quienes parecían tener peso en los dos bandos de federales en cuestión y que, al mismo tiempo, formaban parte de las redes que él estableció durante esos años, según sus propias palabras.

Esta situación nos permite reafirmar lo que enunciamos al comenzar este apartado: la forma de inserción de Mendeville en la sociedad estuvo orientada en dos sentidos. Por un lado, su casamiento con María Sánchez le habría proporcionado la plataforma de despegue para sus negocios, si tomamos en cuenta la fortuna de Mariquita y su vinculación con la sociedad porteña. Por otro, con todo ese capital se inició en la actividad consular, que le abrió las puertas del mundo diplomático y le confirió una aparente neutralidad, permitiéndole intervenir en los asuntos internos en nombre de una gran nación y no a favor de sus propios intereses. Aunque, como veremos más adelante, no le fue fácil convencer de esto a las autoridades de su país.

35 AMREF, Argentine, Correspondance politique, Vol 6, n. ํ 47, págs. 407, 408 y 409. [subrayado nuestro].

36 Ibídem.

37 Tomaremos la noción de "amigos" para referirnos a las personas que están ligadas por afecto, y también en referencia a la acepción de favorable, benévolo o propicio, sin desconocer lo que señala Bott (Familia y ..., pág. 337) respecto del importante problema empírico que la palabra plantea, cuestión a resolver. 


\section{El capital relacional de Mariquita y su beneficio en la inversión matrimonial}

Parece pertinente poner en relieve otra vez el carácter de esta mujer que, cuando sólo contaba con 18 años de edad, se destacó por la defensa que realizó de su derecho al matrimonio.

\section{La red de Mariquita.}

Gracias a sus lecturas, de lo más variadas y modernas, María Sánchez creía en la educación como vehículo de la modernidad. Con esta idea, en 1823 , durante el ministerio de Rivadavia ${ }^{38}$ participó en la fundación de la Sociedad de Beneficencia, bajo cuyo amparo se erigieron un hospital, la cárcel de mujeres, la Casa de niños expósitos y todas las escuelas de niñas de la ciudad. En un primer momento, intervino eligiendo a las trece miembros fundadoras de la Sociedad entre lo más encumbrado de los habitantes porteños ${ }^{39}$ Luego, participó como secretaria e inspectora de escuelas hasta los meses previos a su muerte en 1868.

Su participación en la Sociedad le daba muchas posibilidades de ejercer su influencia. Por un lado, en el seno de la misma Sociedad, podía influir sobre la gente que se beneficiaba con sus servicios; por otro, podía mediar sobre las personas que colaboraban con esta obra, personas que estaban vinculadas a ella por pertenencia a la misma élite y entre las que se establecían relaciones de reciprocidad. ${ }^{40}$

Pero además de esta participación concreta, forma aceptada de injerencia femenina en la vida social, podemos afirmar hoy que Mariquita había fundado su verdadero poder en el culto a las relaciones públicas, que la llevaría a no ausentarse jamás de cuanto acontecimiento social se desarrollarse dondequiera que estuviera (Buenos Aires, Montevideo o Janeiro,

38 Desde 1821 Bernardino Rivadavia era ministro de gobierno del gobernador de Buenos Aires Martín Rodríguez.

39 Sáenz Quesada: Mariquita Sánchez... págs. 87-88.

40 En este punto es útil tener en cuenta los criterios interactivos (contenido, dirección, durabilidad, intensidad y frecuencia de la interacción) de las redes descriptas por Mitchell en su trabajo ya citado "El concepto y el uso de las redes sociales" en: Redes sociales..., sobre todo en lo relativo a la dirección y la implicación o no de reciprocidad de las relaciones, así como su directa vinculación con la frecuencia de los contactos, por ejemplo en este caso, Mariquita y los beneficiados - Mariquita y los "administradores y beneficiarios". 
como se llamaba en aquella época), y a tener al día su correspondencia. Registro de información nada despreciable, según ella misma lo enuncia en una carta a Mendeville: "En el diario que he llevado he escrito mil ochocientas sesenta notas. Sin contar cartas particulares, te puedes imaginar si es broma, a más cuarenta actas: esto es trabajo de cabeza y pluma". ${ }^{4}$ Su casamiento con Mendeville fue el broche de oro y lo que llevaría a W. Parish Robertson a decir en una de sus Cartas de Sud América:

"Casada doña Mariquita con el Cónsul General de Francia, puede inferirse que ejercía gran influencia y gobierno en el elemento extranjero, y seguro estoy de que Lord Palmerston, con su reconocido tacto, su talento y savoir faire no ha puesto en los negocios de Downing Street más destreza y crecimiento que doña Mariquita con su diplomacia femenina en aquella espléndida mansión de la calle Empedrado. Desempeñábase - llegado el caso — con la soltura y sencillez de una condesa inglesa, con el ingenio y vivacidad de una marquesa de Francia o la gracia elegante de una patricia porteña, a punto que cada uno de estos países la hubiera reclamado para sí, de momento, con la nación de sus visitantes." ${ }^{42}$

Como ya lo señalamos más arriba, cuando se casó con Mendeville Mariquita Sánchez ya era una mujer preeminente en la sociedad porteña del siglo pasado; no necesitaba (teóricamente) de su marido para ocupar el lugar que le era propio desde que nació. Sin embargo, su casamiento pudo otorgarle nuevas posibilidades, no sólo para ella sino también para los cinco hijos de su primer matrimonio. Nos atrevemos a pensar que la estrategia de reproducción familiar de los Thompson-Sánchez, luego MendevilleSánchez, estuvo en relación con la estructura del capital que poseía la familia en cuya base, estimamos, el capital social jugaba un rol determinante. Así, juzgamos que no son detalles para olvidar la resolución futura de la vida de la progenie de María Sánchez, en la que tuvo, a nuestro entender, una participación importante como vínculo y orientadora de sus vidas.

Su hija mayor, Clemencia Thompson, se casó en 1826 con el socio de su padrastro, Edouard Loreilhe, y poco tiempo después partieron a vivir a Francia. Su hijo Juan estudió y trabajó varios años en Europa, parte de ellos en París, donde ocupó cargos políticos de importancia y residió en casa de Mme. Castagnet, hermana de Mendeville. ${ }^{43}$ Su tercera hija, Magdalena Thompson, se casó con el marino bretón Chiron de Brossay, quien fre-

41 Vilaseca: Biografías..., "Carta a Mendeville, San Isidro 25 de febrero de 1862".

42 Robertson: Cartas de..., Carta LII, pág. 64.

43 Juan Thompson, luego de un larguísimo noviazgo con Carmen Belgrano, sobrina del general Manuel Belgrano, rompió su compromiso y quedará soltero. 
cuentaba la Tertulia montevideana de Mariquita durante 1841, y luego de su casamiento también se trasladó a Francia. ${ }^{44}$ Florencia, su cuarta hija, se desposó con Faustino Lezica, hijo de una destacada familia criolla, y por último su hija menor, Albina, contrajo enlace con Tressera, un importante hombre de negocios catalán que la llevó a vivir a Barcelona. Sus dos hijos Mendeville, Carlos y Julio, se casaron con americanas. Carlos con la chilena Elisa Alessandri y Julio con la uruguaya Catalina Trápani. De esta forma cumplió uno de sus sueños, ser esta dama europea de la que habla Robertson y que, curiosamente, nunca pasó los limites de Río de Janeiro. Al final de su vida, con la familia esparcida por el mundo, sólo su hija Florencia Thompson de Lezica, viuda desde hacía varios años, le haría compañía. ${ }^{45}$

Teniendo en cuenta lo dicho hasta ahora, podemos observar que este matrimonio fue una inversión substancial para esta mujer que se iba convirtiendo en una verdadera embajadora rioplatense. Es innegable que, como lo señala Ricardo Cicercha, la institución matrimonial otorgaba identidad a la mujer convirtiéndola en sujeto de derecho y permitiéndole además la disputa de la voz familiar. ${ }^{46}$ Pero en este caso nos parece que además, el matrimonio, permitió a Mariquita tener un lugar en la sociedad porteña de la época que parecía considerar que su presencia era valiosa, ya que hacía las veces de centro de encuentro e información social. Su casamiento con Mendeville fue una forma más que interesante de obtener algunas prerrogativas sociales y políticas que sólo un extranjero podía darle, como el privilegio de manejar localmente relaciones e información de corte internacional, ambas cosas constitutivas del capital social.

$\mathrm{Si}$, como lo mencionamos antes, el fuerte de la señora Thompson y Mendeville eran las relaciones públicas, la lista de sus conocidos, amigos y corresponsales no hace más que confirmar lo dicho. Entre ellos estaban: Mme Noguié: dama francesa célebre por sus tertulias en Buenos Aires

44 Es interesante destacar que entre las amistades de Magdalena Thompson en París, donde vivía, se encontraban Merceditas de San Martín, casada con Mariano Balcarce — socio de los negocios en Buenos Aires de su hermano Juan, ya que ambos representaban a esta provincia en España-, Mariano Sarratea y Nieves Spano de Lèfevre, casada con el cónsul francés en Buenos Aires en 1841, quien alquiló la casa de Mariquita.

45 Parecería ser que Florencia persistió en su viudez a pesar de que contaba entre sus más firmes pretendientes a Gervasio Ortiz de Rozas, hermano de Juan Manuel de Rosas, quien en algún momento administró los bienes de Mariquita. (Sáenz Quesada: Mariquita Sánchez..., pág. 194).

46 Cicerchia, Ricardo: "Vida familiar y prácticas conyugales. Clases populares en una ciudad colonial, Buenos Aires, 1800-1810”, Boletín del Instituto de Historia Argentina y Americana Dr. Emilio Ravignani, n. ${ }^{\circ} 2$, tercera serie, Buenos Aires, $1 .^{\text {er }}$ semestre de 1990, pág. 108. 
y Montevideo; Mr. Bouchet Martigny: encargado de negocios de Francia en Montevideo, 1840; Mr. Depouys: agente de Rivera en Buenos Aires; Mr. Delourde: ministro francés, diplomático, alquila la casa de Mariquita; Mr. Capitain: inquilino de Mariquita; Mr. Jean Baptiste Prelig: comerciante francés con el que las Thompson contrataban la importación de muebles, géneros y adornos y que fue inquilino de María Sánchez, además de administrar sus bienes temporalmente y de ocuparse junto a J.B. Alberdi, de la sucesión de Mendeville en Europa. Vivió en París con Mendeville desde que éste se trasladó allí en 1860 hasta su muerte ocurrida en 1863; Mr. Charles Lefevre de Bécourt: encargado de negocios de Francia en 1841, alquiló la casa de Mariquita; Mr. Castelain: arquitecto francés que pasó por Buenos Aires a pedido de Rivadavia y que en ese marco conoció a Mariquita; Mr. Aimé Bonpland: había dado clase de dibujo a sus hijas. Lo vuelve a ver en Montevideo en 1854; Mr. Joseph Guth: artista, apenas llegado de París fue inquilino de Mariquita. ${ }^{47}$

En referencia a su carácter de mediadora y gracias a sus redes, Mariquita consiguió en 1846 cartas de recomendación de Tomás Guido, ministro de Rosas, para el célebre viajero chileno Vicente Pérez Rosales, quien de paso hacia Río de Janeiro había frecuentado su casa acompañando a Sarmiento. ${ }^{48}$ También logró que su yerno Loreilhe fuese nombrado cónsul argentino en Francia en 1854 y, según Sáenz Quesada, "Hasta el biznieto [de Mariquita] escribió a Mariquita para agradecerle la gestión". Intercedió ante el presidente Justo José de Urquiza ${ }^{49}$ por su hijo Juan, que desde hacía algunos años era uno de los cónsules de Buenos Aires en Madrid, para que se le mantuviese en el puesto que ocupaba; en la misma carta pedía idénticos favores para su yerno Juan Tressera, cónsul argentino en Barcelona, y pone a ambos a su disposición "para cualquier cosa que necesite de Europa". ${ }^{50}$ Por último, debe contarse también el nombramiento

47 Vilaseca, C.: Biografías... ; Sáenz Quesada: Mariquita Sánchez..., ; Zavalía Lagos, J.: Mariquita Sánchez y ...; Cutolo, Vicente O: Nuevo diccionario biográfico argentino (1750-1930). Buenos Aires, 1975 y Santillán, D: Enciclopedia argentina. Buenos Aires, 1966.

48 Sarmiento, Domingo Faustino (1811-1888): presidente de la República Argentina de 18681874, educador, escritor literario, estadista y diplomático. Fue maestro y director de escuelas. Fue el encargado de reorganizar la primera Escuela Normal en Chile, en París lo nombraron miembro de la Real Academia Francesa. En junio de 1868 la Universidad de Michigan le otorgó el doctorado honoris causa. Desde la presidencia, en 1868, fomentó la inmigración y la educación. Su producción fué cuantiosa. Wright y Nerhom: Diccionario Histórico...

49 Justo José de Urquiza (1801-1870): presidente de la Confederación Argentina (1854-1860), gobernador de la Provincia de Entre Ríos, general y estadista. Wright y Nerhom: Diccionario Histórico...

50 Sáenz Quesada: Mariquita Sánchez..., pág. 290. 
del pintor francés León Pallière como maestro de pintura en la Escuela Normal de Huérfanas, cargo que obtuvo gracias a su vinculación amistosa con Mariquita, según lo sugiere Julio Payró en su libro Pallière. ${ }^{51}$

\section{Mariquita y el Consulado Francés}

En 1832 fue designado cónsul general de Francia en Buenos Aires el sr. Charles de Laforest, que cumplía en ese momento las mismas funciones en Chile. Sin embargo, el nuevo cónsul no fue aceptado por el gobierno, que argumentaba que las ideas de de Laforest eran reputadas de anti-federales y que ese único hecho impedía su aceptación en Buenos Aires. ${ }^{52}$

A pesar de las excusas formales que dio el gobierno, los cónsules que sucedieron a Mendeville sospecharon que María Sánchez había intervenido ante las autoridades locales para que no se aceptara al nuevo cónsul y así su marido pudiese guardar el cargo. Este episodio sería el primero de una lista que tenía como denominador común la imputación de Mariquita como responsable. Estos acontecimientos nos permitirán ver su grado de familiaridad con las cuestiones consulares, situación que ella misma reconoce cuando en una de las últimas cartas que le dirige a J.B. Alberdi ${ }^{53}$ le dice: “... dos veces ha estado su Consulado por el suelo; yo lo he levantado" ${ }^{4}$; lamentablemente, no menciona los dos momentos, pero sería presumible pensar que sus intervenciones fueron reales y posiblemente hayan tenido que ver con el rechazo de de Laforest.

En 1833, el gobierno francés designó finalmente al sucesor de Mendeville, Charles Vins de Peysac, pero nuevamente surgieron dificultades. Esta vez, el reconocimiento oficial se demoró casi dos años, lo que permitió que Mendeville siguiera en su puesto de Buenos Aires hasta 1835, aunque tres años antes había sido designado cónsul de Guaya-

51 Payró, Julio A.: Palliére. Buenos Aires, 1961, pág. 33.

52 AMREF, Argentine, Correspondance politique, Vol. 6 (1832-1833), carta de Maza a Mendeville, 8 de agosto de 1832 .

53 Alberdi, Juan Bautista (1810-1884): abogado, escritor, intelectual. Representó a la Confederación Argentina ante Francia e Italia entre 1854 y 1861, durante un breve período fue diputado por la provincia del Tucumán en el Congreso Nacional desde 1878 a 1881; sus trabajos publicados llenan veinticuatro volúmenes, incluyendo ensayos políticos y jurídicos que, en muchos casos, proveyeron soluciones aptas para los urgentes problemas argentinos de ese momento y sirvieron para estimular el pensamiento de los intelectuales de su generación y las siguientes. Wright y Nerhom: Diccionario Histórico...

54 Villaseca: Biografías ..., pág. 307. 
quil..$^{55}$ De 1832 a 1835 fueron varios los rumores que circularon en el cuerpo diplomático francés acerca de los favores obtenidos por la señora de Mendeville para mantener a su marido en el Consulado. En cuanto Vins de Peysac tomó posesión de su cargo, escribió al Quai d'Orsay:

“... no es mi intención poner en duda la conducta del señor Mendeville; estoy, al contrario, convencido de que fue franco y leal en todo este episodio [se refiere a la tardanza en su aceptación], pero qué podía hacer él con respecto al interés que la gente de este país tiene por la familia de su mujer, y al deseo bien pronunciado, de parte de algunas personas influyentes, para que el Consulado General de Francia quedase en esa familia". ${ }^{56}$

Es interesante notar que varios de los conceptos vertidos en este informe demuestran, una vez más, los lazos que unían a la familia Mendeville con las personas influyentes de Buenos Aires, y cómo este único hecho fue suficiente para que se sospechara su intervención en el retraso de dos años que tuvo la aceptación oficial del nuevo cónsul francés. Es evidente que la relación privilegiada existía y que pesaba. Y probablemente por esto, la aceptación de Vins de Peysac no fue suficiente para despejar las sospechas que caían sobre Mariquita y que comprometían al cónsul Mendeville ante su gobierno.

Existen otras denuncias algo posteriores acerca de la influencia que María Sánchez ejercía sobre las autoridades en detrimento del nuevo cónsul, pero antes de pasar a ellas, mostraremos otro ejemplo de las diferencias entre Vins de Peysac y la señora de Mendeville.

Las desavenencias entre ambos, llegaron al extremo de no respetar las reglas mínimas de cortesía que debían guardarse. Dice en un informe Vins de Peysac, que en ocasión de una fiesta que había dado en su residencia: “.. yo había invitado también a la velada a la señora de Mendeville y su familia, pero ni ella ni ninguno de los suyos me hicieron el honor de venir; ella estará ofendida por no haberla precisado para las invitaciones...". ${ }^{57}$ Y aquí hay cosas notables. La importancia que otorga el cónsul al episodio, sorprende, y sobre todo que lo comente en un despacho a su

55 En mayo de 1831, Mendeville rechazó la nominación de cónsul de Cartagena de Indias que le hiciera el gobierno francés, y en agosto del mismo año, la designación para el mismo puesto en Nueva Orleans. Lo cierto es que en 1836 era cónsul de Guayaquil y más tarde, de Quito (según el Quai d'Orsay, en 1840. AMREF, Personnel Dossiers Première Serie, Mendeville, 224).

56 AMREF, Argentine, Correspondance politique, vol. 7 (1834-1836), "Division politique" n. ${ }^{\circ} 36 /$ n. ${ }^{\circ} 1,22$ de junio de 1835 , pág. 77.

57 Ibídem, n. ${ }^{\circ} 8$, pág. 243. 
gobierno y si lo hace, es porque le resulta significativo. ¿Cuál era el motivo que Vins de Peysac suponía detrás de la ausencia de Mariquita? hoy podemos pensar que, tal vez, en la explicación que ensaya Vins de Peysac, el "no haberla precisado para las invitaciones", se encuentre una nueva clave sobre el lugar en el que, creemos, residía el poder de Mariquita: lo que nosotros denominamos la manipulación de información y las relaciones públicas. Acaso, la prescindencia de la señora de Mendeville para el manejo de los asuntos relacionados al Consulado francés, marcaba el punto final de su poder sobre dicha cancillería.

En uno de sus últimos informes, de mayo de 1836, Vins de Peysac decía que sus relaciones con el nuevo gobierno - el segundo de Rosas para la Provincia de Buenos Aires- eran buenas, ya que había podido sobreponerse con paciencia a "las más negras intrigas o maquinaciones diabólicas de parte de una mujer más peligrosa aún, porque es del país, y que tiene la rabia en el corazón por no haber podido conservar a su marido en el Consulado General de Francia en Buenos Aires". ${ }^{58}$

Un año después de su puesta en funciones ocurrió un hecho trágico que involucraría nuevamente a la señora de Mendeville. Vins de Peysac murió súbitamente. Algunos dijeron que fue por envenenamiento, y atribuyeron la responsabilidad a Mariquita. Luego de una autopsia, se determinó que la muerte se había producido por una congestión cerebral..$^{59}$ Una vez aclarado esto, el vicecónsul Aimé Roger, que se había quedado a cargo del Consulado general, escribía al Quai d'Orsay con las explicaciones pertinentes al caso:

"La señora de Mendeville, luego de la muerte del sr. Thompson, su primer marido, era todavía, a pesar de su extravagante prodigalidad, dueña de una de las fortunas más grandes del país. Se casó en segundas nupcias con el sr. Mendeville y quiso disfrutar de los únicos placeres que todavía no había probado, la ambición (...) El gobierno francés creyó recompensar generosamente al actual Cónsul de Guayaquil acordándole un puesto en Nueva Orleans, y fue entonces que la señora de Mendeville se convenció de que ella podría probar fácilmente al gobierno francés que su marido era un hombre indispensable en Buenos Aires; de allí surgieron todas la amenazas.

Y ahora lea esta frase de una carta que la señora de Vins de Peysac le escribió a su marido: "ojalá que esa mujer no llegue a emplear contra ti el puñal o el veneno" (frase de una carta que me fue comunicada confidencialmente por el señor de Peysac) y ahora que V.E. me diga si yo podía no sacar a la luz la verdad por todos los medios que están en mi poder, y dejar de publicar oficialmente que fue sólo la apoplejía "fulminante" la que terminó con los días del Señor Vins de Peysac." ${ }_{00}$

58 Ibídem, n. $^{\circ}$ 7, Buenos Aires, 10 mai 1836, pág. 242.

59 Ibídem, n. ${ }^{\circ}$, copia del informe de autopsia a Vins de Peysac.

60 Ibídem, ínterin n. ${ }^{\circ} 3$, págs. 277-278. [el subrayado es nuestro] 
En este largo informe se resumen, en cierta forma, los puntos que tocamos anteriormente. Creemos que el informe muestra bien la estrategia de supervivencia usada por Mariquita y que Roger cree parte de un plan prolijamente perpetrado. Nos parece evidente destacar, por todo lo dicho hasta ahora, que el casamiento de Mendeville y Mariquita les permitió a ambos participar en la política y la sociedad de la época a partir del ensanchamiento de la base de sus relaciones y del inmejorable aprovechamiento de ellas.

\section{Reflexiones finales}

Si Mariquita Sánchez ocupa un lugar en la historia argentina se debe básicamente a que en su casa se escuchó por primera vez el Himno Nacional Argentino o a que participó con Sarmiento en el gran proyecto de educar al pueblo rioplatense. Creemos justo, después de todo lo que hemos podido ver, que mantenga su lugar, además, como ejemplo de alguien que supo utilizar, maximizando hasta los límites posibles, todo su patrimonio personal: el heredado y el construido y adquirido con los años.

Cuando se recorre la vida de este personaje, aparece la tentación de mostrarla como ejemplo de mujer, como caso excepcional, como patriota ilustre, aunque en realidad su caso no haga más que manifestar parte de las reglas de funcionamiento de la sociedad rioplatense que se despojaba con dificultad de su herencia colonial española.

Convendría acá pasar revista rápidamente al patrimonio heredado y enriquecido al que hicimos referencia. Patrimonio que irá cambiando de perfil justo en el momento en el que tomamos el ejemplo. Mariquita heredó el capital económico nada despreciable de su medio hermano Fernando Joseph Del Arco, acrecentado por los negocios de su padre Cecilio Sánchez de Velazco. Además de ello, o mejor dicho junto con él, Mariquita heredó una posición social acomodada a la que le sumó un espacio político criollo que obtuvo con su participación en los acontecimientos de la Independencia junto a su primer marido Martín Thompson. Este camino parece común para algunos hombres de Iberoamérica, según lo señala Diana Balmori en su libro. ${ }^{61}$

61 "En la mayoría de las áreas de Iberoamérica se pueden rastrear conexiones entre las familias gobernantes recién creadas, formadas a fines del siglo XVIII, y los líderes de los partidos políticos de la época nacional.” Balmori, Diana: Las alianzas de familias y la formación del país en América Latina. Chicago, 1984, pág. 53. 
Ahora bien, podríamos decir que al momento de contraer su segundo matrimonio la familia Sánchez-Thompson no era la misma que se había constituído en 1805. Para 1820 el patrimonio de Mariquita, si bien no era despreciable, había mermado. Las causas probables de esta situación, son varias: mala administración, que en cierto sentido podría estar ligada a las capacidades de Thompson para la gestión del patrimonio de su esposa, el aumento de la familia y sobre todo a la colaboración realizada por ésta a la causa de la independencia. Existe otro detalle al que no hay que restar importancia, y es que a poco de llegar a Estados Unidos de América, Thompson enferma gravemente y Mariquita debe hacerse cargo de solventar los gastos derivados de su cuidado y sanación.

Por esto nos parece que el casamiento con Mendeville, hombre sin fortuna, en realidad sólo tuvo un efecto importante como aporte a su capital social. Si tenemos en cuenta las reflexiones de Bourdieu al respecto, podríamos decir que lo de Mariquita fue más bien una estrategia de reconversión de capital a partir del que tenía de su primer matrimonio. Este tipo de estrategia puede describirse como las prácticas que visan a mejorar o conservar una determinada posición social, invirtiendo el capital poseído bajo una particular especie en otra distinta, tendiendo a determinar de esta manera una transformación de la estructura patrimonial. Esto podría reducirse en la frase "transformar para conservar".

Con su segundo matrimonio, María Sánchez, ensanchó las bases de esa influencia y participación que ya tenía, haciéndolas de corte internacional. Ella incluyó en su no menos densa red todo el espectro de relaciones provenientes del campo diplomático, pasando a ser en cierto sentido, la "francesita", como la acusara Rosas en una carta. ${ }^{62}$ Nos atrevemos a pensar que la elección del candidato, estuvo influenciada por lo que Bourdieu llama habitus . Si como lo define Bourdieu "Historia incorporada, hecha natu-

62 Según parece, Rosas y Mariquita entraron en una disputa epistolar desde que Mendeville se exiliara con su familia en Montevideo en 1829 a causa de los problemas entre unitarios y federales. En una carta, Juan Manuel de Rosas le dice: "Conocí antes una María Sánchez buena y virtuosa federal. La desconozco ahora en el billete con tu firma que he recibido de una francesita parlanchina y coqueta" (Zavalía Lagos, J: Mariquita Sánchez y ..., pág. 168). La respuesta de Mariquita fue la siguiente: "No quiero dejarte en la duda de si te ha escrito una francesa o una americana. Te diré que desde que estoy unida a un francés, he servido a mi país con más celo y entusiasmo, y lo haré siempre del mismo modo a no ser que se ponga en oposición de la Francia, pues, en tal caso, seré francesa, porque mi marido es francés y está al servicio de su nación. Tú, que pones en el cepo a Encarnación, debes aprobarme, tanto más cuando no sólo sigo tu doctrina, sino las reglas del honor y del deber. ¿Qué harías si Encarnación se te hiciera unitaria? ...” (Citado por Vilaseca: Biografías..., pág. 14). 
raleza, y de ese modo olvidada como tal, el habitus es la presencia de todo el pasado del cual es el producto: por lo tanto, es el que confiere a las prácticas su independencia relativa en relación a las determinaciones exteriores del presente inmediato" ${ }^{63}$ posiblemente la admiración de Mariquita por Francia, producto de su educación, haya jugado un rol decisivo en la elección del nuevo marido.

Por otro lado, seguramente con el paso del tiempo y como consecuencia de una herencia que se remontaba al siglo anterior, comprendió que parte del poder son las relaciones; y así, siguió abriendo su salón de tertulia, recibiendo a cuanto extranjero estuviese de paso, y cultivando con esmero el arte de la correspondencia. ${ }^{64}$

Sus logros fueron claros y constituyeron el resultado de este complejo circuito de relaciones que le proporcionaron sobre todo beneficios a nivel social y de prestigio ${ }^{65}$ para ella y su descendencia, buenos casamientos y la posibilidad de puestos políticos para sus hijos, convirtiéndola en una power brooker. ${ }^{66}$ La particularidad de su caso es que es ella, una mujer, quien asume la empresa de hacer de su matrimonio y de su familia una buena inversión dentro de las limitaciones impuestas por los usos y costumbres de la época ${ }^{67}$ Ella seleccionó, en todo momento, la mejor alternativa, acorde a sus intereses, entre las que le brindaban sus condiciones objetivas. Al no ceder al deseo de su padre de casarse con el rico sobrino de su madre, Diego Del Arco, Mariquita marcó el rumbo de su vida. Obligada por las circunstancias, apostó todo al ámbito exclusivo de su influencia social. Seguramente creyó que el casamiento con Mendeville le otorgaría no sólo las efímeras pero nada despreciables ventajas de ser "La Francia en Buenos Aires", sino también un acomodo económico que no le trajo. Proba-

63 Bourdieu, Pierre: El sentido práctico. Madrid, 1991, págs. 93-94.

64 Según Zavalía Lagos: Mariquita..., pág. 164, Bernardo de Monteagudo decía en una carta sobre Mariquita: "María Thompson ... ella es la Gaceta de Buenos Aires".

65 Teniendo en cuenta lo que señala Elias, Norbert: "le plus ou le moin de prestige dont un homme dispose dans une formation sociale, est l'expression de son pois dans l'equilibre multipolaire des tensions qui agitent son groupe, de sa chance d'exercer son influence sur les autres ou d'etre obligé de se soumettre à leur influence." La société de Cour, Paris, 1985, págs. 92-93.

66 Power brooker: manipulador profesional de personas e información que consigue comunicación para beneficiarse. Boissevain, J.: Friend of friends. Oxford, 1974, pág. 148.

67 Teniendo en cuenta el dato que aporta Ricardo Cicerchia sobre el rumbo tomado por las nuevas investigaciones sobre historia social de la familia en América Latina, en las que se señala la existencia de "Elevadísimos porcentajes de mujeres jefas de hogar, ... sugiriendo una gran autonomía de la mujer". Cicerchia: "Vida familiar y prácticas conyugales...", pág. 92. Pensamos que detrás de los matrimonios de la Sánchez, sobre todo del último, hay un elemento nuevo que se refiere a la "planificación" de su matrimonio con el objetivo de restructurar su familia. 
blemente en la frustración de no haberlo logrado, se asentaran las quejas que permanentemente deja ver en sus cartas.

El caso María Sánchez parece presentar así algunas particularidades respecto de los modelos que describen Balmori y Lidney, entre otros, ya que con un itinerario familiar parecido al descrito por estos autores ${ }^{68}$ determina con su decisión de casarse con Thompson no sólo un cambio en el rumbo esperado de una familia de la época, sino que, más aún, indica la aparición de una nueva modalidad de matrimonio en la que el uso y la costumbre coloniales de las clases "acomodadas" parecen no estar presentes. ${ }^{69}$ $\mathrm{Al}$ igual que en la elección de casarse con Mendeville, en la iniciativa de casarse con Thompson, patriota de la primera hora, está presente la injerencia del habitus de una mujer "ilustrada" criolla.

Parecería ser que en 1868, con su desaparición, la intensa red que había construido durante su larga vida se desdibujó, quedando tan sólo en el recuerdo un buen apellido criollo ${ }^{70}$. Quizás la "desaparición" de esta familia sea tan sólo el producto de los cambios que sufrió la sociedad rioplatense a partir del momento en el que se separa el matrimonio Mendeville-Sánchez. El año de la partida de Mendeville, 1835, coincide con el segundo gobierno de Rosas, inicio de un largo proceso de cambios estructurales para la sociedad porteña del diecinueve.

Con respecto a Mendeville, su peculio parece mucho menor que el de María Sánchez y circunscripto exclusivamente al ámbito del Río de la Plata, lo que reduce aún más su horizonte. Durante sus casi veinte años de estancia en el Río de la Plata, logró nombramientos consulares y un cierto poder

68 En el sentido que lo señalan los autores para las Familias recientes. La de SánchezCárdenas, constituida hacia finales del siglo XVIII (1771) entre peninsular y criolla. En el caso de Magdalena Trillo, española y viuda acaudalada residente en el lugar hacía varios años; padre que se dedica a los negocios comerciales de su esposa, a los que suma la administración de un campo (Balmori: Las alianzas..., pág. 27) —como señalaba Thompson en el juicio de disenso—, con cargas públicas y una segunda generación que en este caso no se puede acomodar como desea y es costumbre, pero que cumple con la característica de participar en la emancipación y en el gobierno independiente, del nuevo espacio político.

69 Es muy interesante tener en cuenta aquí las apreciaciones hechas por Cicerchia ("Vida familiar y prácticas conyugales...", págs. 93 y 94), que hace una descripción interesante del matrimonio durante la colonia y de los cambios sufridos a partir de la real pragmática de 1776 “... extendida a los territorios de ultramar dos años después de su sanción” y que respondía a la intención de la monarquía de evitar los matrimonios "desiguales, inconvenientes para la estructura jerárquica de la sociedad, e inspirados en la absoluta e indisciplinada libertad con la cual los jóvenes apasionados e incapaces se comprometían...ofendiendo el honor familiar y amenazando la integridad del estado".

70 Cuatro de los cinco hijos de Mariquita y Thompson terminaron sus días seguramente lejos de Buenos Aires; probablemente sólo Florencia Thompson de Lezica permaneció allí, lo que explicaría que la familia Lezica conserve la mayor parte de los documentos que se relacionan con Mariquita Sánchez. 
político y económico, además de constituir una familia que no siempre estuvo a su lado. Si como lo afirma Zacarias Moutoukias para la época colonial "las redes de vínculos primarios cuyo núcleo eran las parentelas constituían para los miembros de los grupos dominantes el principal recurso con el cual organizaban sus negocios", ${ }^{71}$ podríamos afirmar que la participación de Mendeville en el comercio local ${ }^{72}$ y las posibles consecuencias de esas actividades en su red de relaciones fueron en un principio fruto de su propio emprendimiento, pero, evidentemente, la fortuna de su esposa y su influencia deben haber colaborado. Finalmente, lo que parece más claro a simple vista es que, durante los años que pasó en el Río de la Plata, su posición - que como observamos tenía el doble carácter de criolla y extranjeray su prestigio le aseguraron una vida políticamente activa y acomodada en lo social y económico, aunque en este último aspecto ciertamente menos. $\mathrm{Su}$ casamiento con Mariquita le dejó, además de tres hijos, una carrera diplomática que comenzó en Buenos Aires, presumiblemente gracias a la influencia de su esposa, y que terminó en Quito a finales de 1850.

El ejemplo elegido para este trabajo nos ha permitido ver la existencia de una modalidad particular de matrimonio en el que el interés de la unión no sólo estaba dado por sus posibilidades económicas, sino, más bien, por el capital relacional que se incorporaba y por las posibilidades reales de reconvertirlo. Podríamos decir que las bases sobre las que construye la estrategia de reproducción familiar son las del capital social. El cultivo de las relaciones personales y de la correspondencia aseguraron a la primera interesada de la pareja, Mariquita, la permanencia activa en la vida socio-cultural porteña, aún cuando su economía estuviera comprometida seriamente. De manera tal que en la Buenos Aires del diecinueve nadie parecía desconocer, ni dudar, del lugar preponderante que le cabía a doña Mariquita, a la que el viajero francés A. Isabelle llamó "La estrella del sur".

71 Moutoukias, Z: "Redes, autoridad y negocios: racionalidad empresaria y consenso colonial en Buenos Aires (segunda mitad del siglo XVIII)". Annales, Economie, Société, Civilization, n. ${ }^{\text {4-5, }}$ París, 1992.

72 Desconocemos si el hecho de haber sido nombrado inspector general de Comercio de Francia en Buenos Aires, en 1825, tenía relación o afectaba de alguna manera la posibilidad de tener una casa de comercio en su lugar de residencia. Pero sí sabemos que como cónsul general de Francia no podía comerciar. Ver "Les devoirs des consuls" en Les affaires étrangers et le corp diplomatique français. Tomo II De l'Ancien Régime au Second Empire. Dir. Jean Baillon, París, 1984. 